\title{
PREVALENCE OF PREHYPERTENSION AMONG SCHOOL CHILDREN OF RURAL SOUTH KERALA, INDIA
}

\author{
Vasantha Mallika M. C1, Siva Sree Ranga M. K2, Danita Anna Thampan ${ }^{3}$ \\ ${ }_{1}^{1}$ Associate Professor, Department of Community Medicine, Dr. SMCSI Medical College, Karakonam. \\ ${ }^{2}$ Assistant Professor, Department of Anatomy, Dr. SMCSI Medical College, Karakonam. \\ ${ }_{3}^{3}$ MBBS Student, Dr. SMCSI Medical College, Karakonam.
}

\section{ABSTRACT}

\section{BACKGROUND}

Hypertension, a silent killer is a major public health problem. Adult hypertension may start early in life. Literature shows an increasing trend in prevalence of hypertension among children. Early detection of prehypertensives will help in prevention of hypertension by adopting lifestyle modifications. As there is paucity in studies on prevalence of prehypertension among children of rural South Kerala, this study has been planned.

Objectives-1. To study the prevalence of prehypertension among school children of age 9-17 years in Perumkadavila block, Thiruvananthapuram District. 2 . To identify the risk factors of prehypertension in the study population.

\section{MATERIALS AND METHODS}

A cross sectional study was conducted among 1600 school children of age group 9-17 years of Perumkadavila Block, South Kerala, India selected by Multistage sampling during a period of six months from June 2016. Data were collected using Modified WHO Global School-based Student Health Survey Questionnaire, including Anthropometric and BP measurements. Prehypertension was defined as Systolic BP 120-139 mmHg and Diastolic BP 80-89 mmHg. Statistical analysis was done using SPSS package.

\section{RESULTS}

Out of 1600 study subjects, $49.5 \%$ were boys and 50.5\% were girls. Prevalence of prehypertension and hypertension was $6.125 \%$ (boys $-1.625 \%$, girls $-4.5 \%$ ) and $4.5 \%$ (boys $-1.875 \%$, girls- $2.625 \%$ ) respectively. Age (' $Z$ ' 3.42, $\mathrm{P}<0.001$ ), Female gender ('Z' 0.610 , P <0.05), Overweight/Obesity ('Z' 158.8, P <0.001), Low Socioeconomic status ( $Z$ ' 158.8, P <0.001) and Family history of Diabetes, Hypertension or Coronary Artery Disease (' $\mathrm{Z}$ ' 89.38, $\mathrm{P}<0.001$ ) were the significant risk factors for prehypertension and hypertension.

\section{CONCLUSION}

High prevalence of prehypertension and hypertension and associated risk factors among school children of the study area need targeted interventions to reduce consequences. The findings were used in developing awareness programs for prevention of morbidity and mortality due to prehypertension and its complications.

\section{KEYWORDS}

Prehypertension, Prevalence, Hypertension, Lifestyle Modification.

HOW TO CITE THIS ARTICLE: Mallika VMC, Ranga SSMK, Thampan DA. Prevalence of prehypertension among school children of rural south Kerala, India. J. Evolution Med. Dent. Sci. 2017;6(25):2078-2082, DOI: 10.14260/Jemds/2017/452

\section{BACKGROUND}

Hypertension, a silent killer, is a major public health problem ${ }^{1}$ worldwide and is one of the risk factors for coronary artery disease and cerebrovascular disease. High blood pressure is the leading cause of death and disability worldwide and accounted for 9.4 million deaths and $7 \%$ of disability adjusted life years (DALYs) in 2010.2 Development of adult hypertension may start very early in life causing premature deaths among adults throughout the world. ${ }^{3}$

The prevalence of hypertension among children is 4 to $15 \%$ worldwide. 4

Financial or Other, Competing Interest: None.

Submission 20-02-2017, Peer Review 15-03-2017,

Acceptance 22-03-2017, Published 27-03-2017.

Corresponding Author:

Dr. Vasantha Mallika M. C,

Siva Sree Sadanam

Vellarada,

Thiruvananthapuram-695505,

Kerala, South India.

E-mail: dr.mcvasanthamallika@gmail.com

DOI: $10.14260 /$ jemds $/ 2017 / 452$
In India, hypertension is the leading risk factor for Noncommunicable Disease and is estimated to be attributable for nearly $10 \%$ of all deaths. ${ }^{5}$ Literature shows an increasing trend in the prevalence of hypertension among children during recent decades.6,7

Many researchers studied the patterns of blood pressure and the determinants in childhood and adolescence. 8,9

Studies have shown that the level and patterns of blood pressure among children and adolescents may vary from population to population. ${ }^{10}$

Prevalence of childhood hypertension was found to be 5$10 \%$ in developing countries and $1-2 \%$ in developed countries. ${ }^{11}$ The prevalence of childhood hypertension in various Indian studies range from $0.96 \%$ to $11.4 \%$ respectively. 12

Most of the risk factors of hypertension are preventable or modifiable if appropriate lifestyle modification is applied. As most of the behaviours begin in early adolescence, it is the appropriate time for appropriate intervention. It will be ideal to find out the prevalence of prehypertension among children so that timely lifestyle modifications will prevent them from becoming hypertensive in adulthood.

No relevant data are available on the prevalence of prehypertension in children of rural South Kerala. In this context, this study had been planned to find out the prevalence 
of prehypertension among school children from rural areas of Perumkadavila block panchayath, in South Kerala.

\section{Objectives}

1. To study the prevalence of prehypertension among school children of age 9-17 years in Perumkadavila block, Thiruvananthapuram District.

2. To identify the risk factors of prehypertension in the study population.

\section{MATERIALS AND METHODS}

\section{Study Design}

Cross sectional study.

\section{Study Area}

Schools from Perumkadavila Block Panchayath located 35 kilometres towards south from Thiruvananthapuram, capital of Kerala. The Perumkadavila Block Panchayath is comprised of five Grama Panchayaths. A total of 45 schools including Government, Private and Aided schools are there in this area.

\section{Study Population}

Among the students from Government, Private and Aided schools of Perumkadavila Block Panchayath, a sample of study subjects of the age group 9-17 years maintaining proportion from them was selected.

\section{Exclusion Criteria}

Those who were not willing to participate in the study.

\section{Selection of Study Subjects}

Multistage Random sampling method was used.

\section{Sample Size}

Prevalence of Prehypertension among children is $20.7 \%$ to $24.5 \%$ in studies ${ }^{13}$ from developing countries.

Sample size for the present study was calculated using the formula $4 \mathrm{PQ} / \mathrm{d} 2$.

Prevalence, $\mathrm{P}=20$.

$\mathrm{Q}=100-\mathrm{P}=80$.

Effect Size $=10 \%$ of $P=2$.

Sample size $=(4 \times 20 \times 80=6400) / 4=1600$

The sample size $=1600$.

\section{Study Duration}

A period of six months from June 2016.

\section{Study Tool}

Pretested questionnaire based on Modified WHO Global School-based Student Health Survey Questionnaire, including Anthropometric and BP measurements.

Before starting the study, Ethics Committee clearance was obtained from the Institutional Ethics Committee. Informed consent was taken from the children. In the case of children below 12 years of age, informed consent was obtained from the parents and assent from the students.

\section{Method of Data Collection}

The parents, schoolchildren, and responsible school authorities were sensitised about the aim, significance and the timeline for the study.

The school children were interviewed and examined by the investigator. Each participant was comfortably seated. Blood Pressure was measured on the left arm in a sitting position after 5 minutes of rest in a quiet room using reliable sphygmomanometer. Systolic blood pressure (SBP) and diastolic blood pressure (DBP) were recorded.
Prehypertensives were repeated for second BP measurement for confirmation.

Standardised Techniques were used for data on weight and height.

\section{Study Variables}

Dependent variables: Blood pressure recording (SBP in $\mathrm{mmHg}$, DBP in mmHg, hypertension, and prehypertension). Independent variables: Age (in years as stated by the student), Gender, Father's education (as stated by the student), Mother's education (as stated by the student), Economic status (BPL/APL examining the ration card).

\section{The questionnaire was used to get information about the following variables also}

Hypertensive status of parents, Diabetic status of parents, GDM status of mother, Outdoor activities, Dietary factors, Mode of transportation.

Anthropometric measurements (Height was measured using stadiometer, Weight using weighing machine and BMI was calculated from the height and weight in $\mathrm{kg} / \mathrm{m}^{2}$ ).

The cut-off value for Blood Pressure ${ }^{14}$ was taken referring text book of Paediatrics by O.P Ghai and following the NHBPEP Classification 15 of Prehypertension and Hypertension in Children and Adolescents as shown below-

- Normal Blood Pressure is less than 90th percentile.

- Prehypertension was defined as average Systolic Blood Pressure (SBP) or Diastolic Blood Pressure (DBP) levels that are greater than or equal to 90th percentile but less than 95th percentile for gender age and height.

- Hypertension was defined as average SBP or DBP greater than or equal to $95^{\text {th }}$ percentile for gender, age and height on at least three separate occasions.

Statistical Analysis was done using SPSS -16 Package.

\section{RESULTS}

The cross sectional study was conducted among 1600 school children from Perumkadavila Block panchayath to find out the prevalence of Prehypertension and the risk factors. It was found that-

- $\quad$ No. of Boys $=792(49.5 \%)$

- No. of Girls $=808(50.5 \%)$

- $\quad$ Prevalence of Prehypertension $=98(6.125 \%)$

- $\quad$ Prevalence of Hypertension $=72(4.5 \%)$

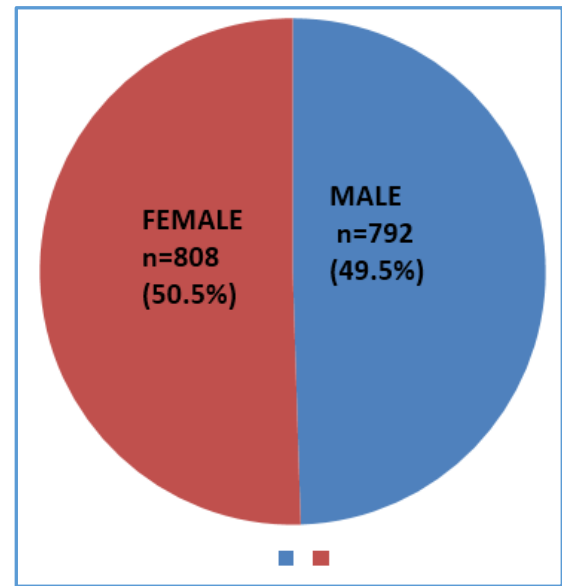

\section{Figure 1. Gender wise Distribution of Study Subjects}

Out of the total 1600 study subjects, 792 (49.5\%) were male and $808(50.5 \%)$ were female. 
Among 792 boys, 26 (3.28\%) were prehypertensives and among girls $72(8.91 \%)$ were prehypertensives.

\begin{tabular}{|c|c|c|c|c|c|c|}
\hline & $\begin{array}{c}\text { Systolic BP } \\
\text { in mmHg }\end{array}$ & $\begin{array}{c}\text { DBP } \\
\text { in } \mathbf{m m H g}\end{array}$ & $\begin{array}{c}\text { Height in } \\
\text { Centimetres }\end{array}$ & $\begin{array}{l}\text { Weight in } \\
\text { Kilograms }\end{array}$ & $\begin{array}{l}\mathrm{BMI} \text { in } \\
\mathrm{Kg} / \mathrm{m}^{2}\end{array}$ & $\begin{array}{l}\text { Age in } \\
\text { years }\end{array}$ \\
\hline MEAN & 88.6 & 52.1 & 147 & 42.4 & 18.9 & 12.5 \\
\hline SD & 11.4 & 46.1 & 18.1 & 17.1 & 4.41 & 3.63 \\
\hline $5^{\text {th }}$ Percentile & 80 & 50 & 118 & 20 & 13.6 & 9 \\
\hline $10^{\text {th }}$ Percentile & 85 & 50 & 122 & 22.2 & 14.3 & 10 \\
\hline 20th Percentile & 90 & 60 & 129 & 26 & 15.2 & 11 \\
\hline 30th Percentile & 95 & 60 & 135 & 30 & 16 & 12 \\
\hline 40th Percentile & 100 & 60 & 142 & 35 & 17 & 11 \\
\hline 50 th Percentile & 100 & 60 & 149 & 40 & 18 & 14 \\
\hline $60^{\text {th }}$ Percentile & 105 & 70 & 154 & 46 & 19.1 & 15 \\
\hline 70th Percentile & 110 & 70 & 159 & 51 & 20.3 & 16 \\
\hline $80^{\text {th }}$ Percentile & 110 & 75 & 160 & 57 & 22.2 & 16 \\
\hline 85th Percentile & 115 & 80 & 163 & 60 & 22.5 & 17 \\
\hline 90th Percentile & 120 & 80 & 164 & 65 & 23.4 & 17 \\
\hline 95 th Percentile & 120 & 80 & 166 & 70 & 25.4 & 17 \\
\hline \multicolumn{7}{|c|}{ Table 1. Blood Pressure and Anthropometric Measures of Participants } \\
\hline
\end{tabular}

The mean age of the study subjects was 12.5 years, Mean Systolic BP was 88.6 mmHg, Mean Diastolic BP $52.1 \mathrm{mmHg}$, Mean Height $147 \mathrm{~cm}$, Mean weight $42.4 \mathrm{~kg}$ and Mean BMI $18.9 \mathrm{~kg} / \mathrm{m}^{2}$.(Table 1).

\begin{tabular}{|c|c|c|c|c|c|c|}
\hline \multirow{2}{*}{ Classification } & \multicolumn{2}{|c|}{ Male } & \multicolumn{2}{c|}{ Female } & \multicolumn{2}{c|}{ Total } \\
\cline { 2 - 7 } & Number & Percent & Number & Percent & Number & Percent \\
\hline $\begin{array}{c}\text { Normal } \\
\text { (SBP \& DBP <90th percentile) }\end{array}$ & 736 & 46 & 694 & 43.375 & 1430 & 89.375 \\
\hline $\begin{array}{c}\text { Prehypertension } \\
\text { (SBP or DBP } \geq 90 \text { th percentile but <95th } \\
\text { percentile) }\end{array}$ & 26 & 1.625 & 72 & 4.5 & 98 & 6.125 \\
\hline $\begin{array}{c}\text { Hypertension (SBP \&/or DBP } \geq 95 \text { th } \\
\text { percentile) }\end{array}$ & 30 & 1.875 & 42 & 2.625 & 72 & 4.5 \\
\hline Total & $\mathbf{7 9 2}$ & $\mathbf{4 9 . 5}$ & $\mathbf{8 0 8}$ & $\mathbf{5 0 . 5}$ & $\mathbf{1 6 0 0}$ & $\mathbf{1 0 0}$ \\
\hline \multicolumn{2}{|r|}{} \\
\hline
\end{tabular}

SBP- Systolic Blood Pressure; DBP - Diastolic Blood Pressure.

A total of 1600 subjects were studied of which 792 (49.5\%) were male and 808 (50.5\%) were female.

Prevalence of Prehypertension was 98 (6.125 \%) with 26 male (1.625\%) and 72 female (4.5\%) prehypertensives.

Prevalence of Hypertension was 72 (4.5\%) including 30 male (1.875\%) and 42 (2.625\%) female hypertensives.

\begin{tabular}{|c|c|c|c|c|c|}
\hline \multirow{2}{*}{ Category } & \multirow{2}{*}{$\begin{array}{l}\text { Component } \\
\text { of Category }\end{array}$} & \multicolumn{2}{|c|}{ Prehypertensive Group } & \multirow{2}{*}{ ' $\mathbf{z}$ ' } & \multirow{2}{*}{ Significance } \\
\hline & & Number & Percentage & & \\
\hline \multirow{2}{*}{ Age } & $<12$ & 12 & 12.2 & \multirow{2}{*}{3.42} & \multirow{2}{*}{$\mathrm{P}<0.001$} \\
\hline & $\geq 12$ & 86 & 87.8 & & \\
\hline \multirow{2}{*}{ Gender } & Male & 26 & 26.5 & \multirow{2}{*}{0.610} & \multirow{2}{*}{$P>0.05$} \\
\hline & Female & 72 & 73.5 & & \\
\hline \multirow{2}{*}{ BMI } & $\geq 23$ & 75 & 76.5 & \multirow{2}{*}{158.8} & \multirow{2}{*}{$\mathrm{P}<0.001$} \\
\hline & $<23$ & 23 & 23.5 & & \\
\hline \multirow{2}{*}{$\begin{array}{c}\text { Family history of } \\
\text { HT, DM CAD }\end{array}$} & Present & 74 & 75.5 & \multirow{2}{*}{89.38} & \multirow{2}{*}{$\mathrm{P}<0.001$} \\
\hline & Absent & 24 & 24.5 & & \\
\hline \multirow{2}{*}{ Socioeconomic status } & High & 23 & 23.5 & \multirow{2}{*}{158.8} & \multirow{2}{*}{$P<0.001$} \\
\hline & Low & 75 & 76.5 & & \\
\hline
\end{tabular}

BMI-Body Mass Index, HT- Hypertension, DM - Diabetes Mellitus, CAD- Coronary Artery Disease

With regard to gender, $26.5 \%$ of prehypertensives were male and $73.5 \%$ of prehypertensives were female and the difference was statistically significant $(\mathrm{P}<0.05)$.

Age, female gender, BMI and family history of Diabetes, Hypertension or Coronary Artery disease were showing statistically significant $(\mathrm{P}<0.001)$ association with prehypertension in the present study.

Low Socioeconomic status was seen as a significant risk factor for prehypertension in this study. 


\section{DISCUSSION}

In the present study, the prevalence of prehypertension among 1600 school children was $6.125 \%$, prevalence of hypertension was $4.5 \%$. The prevalence of systolic hypertension (SBP>140) was $7.84 \%$ and diastolic hypertension (DBP >90) $2.15 \%$ in a study conducted by A. K. Singh et al. ${ }^{15}$ A study conducted among children from rural areas by Mohan et al showed a prevalence of 2.56\%.16 Patil and Garg reported in their study ${ }^{17}$ that prevalence of hypertension among children aged 6-16 years was 3\%.

Gender wise, the present study showed a higher prevalence of prehypertension and hypertension among females than males. Prevalence of prehypertension was $6.125 \%$ with 26 males (1.625\%) and 72 females (4.5\%). The $72(4.5 \%)$ hypertensive children included 30 boys $(1.875 \%)$ and $42(2.625 \%)$ girls.

But several studies reported higher prevalence of blood pressure among males than females during adolescence and early adulthood.18,19

In the present study, prehypertension and hypertension showed significant association with high Body Mass Index. Previous studies also showed that blood pressure increased significantly as Body Mass Index (BMI) increased.20-22 A study conducted among youth showed that there is $14 \%$ increased chance for prehypertension or hypertension for a unit increase in BMI. A study by Berenson et $\mathrm{al}^{23}$ showed high BMI as one of the strongest risk factors of hypertension.

Low Socioeconomic status was seen as a significant risk factor for prehypertension in this study. Recent studies ${ }^{24}$ from India reported that belonging to low socioeconomic group and being illiterate are independent risk factors for cardiovascular diseases.

Family history of Diabetes, Hypertension or Coronary Artery Disease were showing statistically significant association with prehypertension in the present study. Some other studies also show similar finding. 25

Low physical activity did not evolve as significant risk factor in this study.

\section{CONCLUSION}

High prevalence of prehypertension and associated risk factors among school children of rural areas need targeted interventions to reduce cardiovascular risk. It is beneficial if every health facility makes attempts for routine recording of blood pressure of school children so that prehypertensives may be detected early and subjected to lifestyle modifications to prevent morbidity and mortality due to hypertension and prehypertension. Health education programs may be given importance from the Departments of Health Services and Department of Education for evolving a generation free of risk factors for Noncommunicable diseases.

\section{ACKNOWLEDGEMENT}

We acknowledge with gratitude the help of the school authorities, students and parents for their kind cooperation.

\section{REFERENCES}

[1] Lawes CM, Hoorn VS, Law MR, et al. Blood pressure and the global burden of disease 2000. Part II: estimates of attributable burden. J Hypertens 2006;24(3):423-30.
[2] Lim SS, Vos T, Flaxman AD, et al. A comparative risk assessment of burden of disease and injury attributable to 67 risk factors and risk factor clusters in 21 regions, 1990-2010: a systematic analysis for the global burden of disease study 2010. Lancet 2012;380(9859):2224-60.

[3] Chobanian AV, Bakris GL, Black HR, et al. The seventh report of the joint national committee on prevention, detection, evaluation, and treatment of high blood pressure: the JNC 7 report. JAMA 2003;289(19): 2560-72.

[4] Borici S, Agaoglu NB, Baykan OA, et al. Blood pressure and anthropometric measurements in Albanian versus Turkish children and adolescents. Acta cardiologica 2009;64(6):747-54.

[5] Patel V, Chatterji S, Chisholm D, et al. Chronic diseases and injuries in India. Lancet 2011;377(9763):413-28.

[6] Chiolero A, Paradis G, Madeleine G, et al. Discordant secular trends in elevated blood pressure and obesity in children and adolescents in a rapidly developing country. Circulation 2009;119(4):558-65.

[7] Ostchega Y, Carroll M, Prineas RJ, et al. Trends of elevated blood pressure among children and adolescents: data from the national health and nutrition examination survey 1988-2006. Am J hypertens 2009;22(1):59-67.

[8] Chadha SL, Vasan RS, Sarma PS, et al. Age-and heightspecific reference limits of blood pressure of Indian children. Natl Med J india 1999;12(4):150-6.

[9] Lawlor DA, Smith GD. Early life determinants of adult blood pressure. Curr opin nephrol hypertens 2005;14(3):259-64.

[10] Sung RYT, Lam YM, Leung SSF. Blood pressure in Hong Kong Chinese children: correlation with anthropometric data. JHK coll cardiol 1994;2:99-106.

[11] Luma GB, Spiotta RT. Hypertension in children and adolescents. Am fam physician 2006;73(9):1558-68.

[12] de onis M, Blossner M. Prevalence and trends of overweight among preschool children in developing countries. Am J clin nutr 2000;72(4):1032-9.

[13] Mbolle BFE, Okoko AR, Babela JRM, et al. Prehypertension and hypertension among school children in Brazzaville, Congo. International Journal of hypertension Article ID 803690, 2014;2014:6.

[14] National High Blood Pressure Education Program Working Group on High Blood Pressure in Children and Adolescents. The fourth report on the diagnosis, evaluation, and treatment of high blood pressure in children and adolescents. Pediatrics 2004;114(2 Suppl 4th report):555-76.

[15] Singh Ak, Maheswari A, Sarma N, et al. Lifestyle associated risk factors in adolescents. Indian J paediatr 2006;73(10):901-6.

[16] Mohan B, Kumar N, Aslam N, et al. Prevalence of sustained hypertension and obesity in urban and rural school going children in Ludhiana. Indian heart J 2004;56(4):310-4. 
[17] Patil RR, Garg BS. Prevalence of hypertension and variation in blood pressure among school children in rural area of Wardha. Indian J public health 2014;58(2):78-83.

[18] Percy C, Freedman DS, Gilbert TJ, et al. Prevalence of hypertension among Navajo Indians: finding from the Navajo and nutritional survey. J Nutr 1997;127(10 Suppl):2114S-9S.

[19] Sugarman JR, White LL, Gilbert TJ. Evidence for a secular change in obesity, height, and weight among Navajo Indian schoolchildren. Am J clin nutr 1990;52(6):960-6.

[20] Brown CD, Higgins M, Donato KA, et al. Body mass index and the prevalence of hypertension and dyslipidemia. Obes Res 2000;8(9):605-19.

[21] Holm SS, Sorensen TI, Jensen G, et al. Independent effects of weight change and attained body weight on prevalence of arterial hypertension in obese and nonobese men. BMJ 1989;299(6702):767-70.
[22] Sreedharan J, Mathew E, Muttappallymyalil J, et al. Determinants of blood pressure among youth in Ajman, UAE. Natl J epidemiology 2010;1(1):17-21.

[23] Berenson GS, Srinivasan SR, Bao W, et al. Association between multiple cardiovascular risk factors and atherosclerosis in children and young adults. The Bogalusa heart study. N Engl Med 1998;338(23): 1650-6.

[24] Pais P, Pogue J, Gerstein H, et al. Risk factor for acute myocardial infarction in Indians: a case control study. Lancet 1996;348(9024):358-63.

[25] Rastogi T, Reddy KS, Vaz M, et al. Diet and risk of ischemic heart disease in India. Am J clin nutr 2004;79(4):582-92. 